\section{Intravitreal triamcinolone for diffuse diabetic macular oedema}

\begin{abstract}
Aim To evaluate the efficacy of intravitreal triamcinolone (IVTA) for the treatment of diffuse diabetic macular oedema (DME) refractory to conventional argon macular laser therapy.

Methods A prospective, consecutive, and noncomparative case series was undertaken involving 38 eyes of 38 patients with refractory DME. Triamcinolone acetonide $(4 \mathrm{mg})$ in $0.1 \mathrm{ml}$ was injected intravitreally. LogMar visual acuity (VA) and macular thickness measured by ocular coherence tomography (OCT) were assessed preoperatively and postoperatively at 1,3 , and 6 months.

Results All patients completed 6 months of follow up. VA (mean \pm SD) improved from $0.905 \pm 0.23$ to $0.605 \pm 0.28,0.555 \pm 0.29$, and $0.730 \pm 0.30$ at 1,3 , and 6 months, respectively. Macular thickness baseline (mean \pm SD) on OCT was $418.7 \pm 104.2 \mu \mathrm{m}$ and this decreased to $276.9 \pm 72.6 \mu \mathrm{m}, 250.6 \pm 53.1 \mu \mathrm{m}$, and

$308.8 \pm 87.3 \mu \mathrm{m}$ at 1,3 , and 6 months, respectively.

Conclusions IVTA may be a potential temporary treatment for refractory DME. It is effective in decreasing macular thickness and improving VA but the effect lasts
\end{abstract}

Department of
ophthalmology, Cork University Hospital, Cork, Ireland

Correspondence: SK Gibran, Department of ophthalmology, Cork University Hospital, Cork, Ireland Tel: 00353214546400 ; Fax: 00353214922656. E-mail: syedgibran@ yahoo.com

Received: 24 December 2004

Accepted: 25 May 2005 Published online: 8 July 2005
SK Gibran, A Cullinane, S Jungkim and PE Cleary

the western world ${ }^{1}$ and diffuse DME is one of the main reasons for reduced vision in patients with disease duration of 20 years or more. While the Early Treatment Diabetic Retinopathy Study (ETDRS) demonstrated that grid laser was beneficial in reducing visual loss in this group, a number of studies have shown that eyes with diffuse macular oedema carry a particularly poor long-term prognosis despite argon laser photocoagulation. ${ }^{2}$ Intravitreal Triamcinolone Acetonide (IVTA) has been used in the treatment of cystoid macular oedema (CMO) secondary to retinal vascular occlusive disease, ${ }^{3}$ pseudophakic $\mathrm{CMO},{ }^{4}$ and $\mathrm{CMO}$ in retinitis pigmentosa. ${ }^{5}$ More recently, Ciardella et $a l^{6}$ described the beneficial effects of IVTA in refractory DME with hard exudate formation. In this study, we prospectively examined the effects of a single dose of IVTA on macular thickness and visual outcome in patients with refractory diffuse macular oedema without exudate.

Materials and methods

We prospectively examined 38 eyes of 38 patients both clinically and angiographically, according to ETDRS criteria from January 2001 to December 2003. All eyes enrolled had DME for a minimum of 3 months despite at least two macular grid laser treatments. The effects of a single dose of IVTA were examined. Patients who demonstrated a recurrence of DME were not reinjected during the course of this study. All patients were clinically assessed and managed by one of two authors (SKG, PEC). Patients were fully informed about the experimental nature of this intervention and consented accordingly. All patients received ocular examination including best-corrected visual acuity (VA) (ETDRS chart), applanation tonometery, slitlamp biomicroscopy, lens evaluation, and dilated posterior pole examination. 
The VA was $6 / 24$ or worse and constant for a minimum of 3 months. All patients had systolic and diastolic blood pressure of less than 150 and $90 \mathrm{mmHg}$, respectively. All patients had $\mathrm{HbA1c}$ less than $9 \%$. No eyes had a history of ocular hypertension or glaucoma. The topographic mapping protocol of OCT software was used for each eye (6 radial lines, OCT 2, Carl Zeiss Meditec AG, Germany). This technique has been described previously. ${ }^{7}$ All patients had central macular thickening of more than $250 \mu \mathrm{m}$.

IVTA injection was performed in the operating theatre under strict asepsis on all patients. The eyelids and ocular surface were sterilised with $5 \%$ povidone and iodine solution after instilling topical amethocaine $1 \%$ drops. A sterilised eye drape was applied. Triamcinolone acetonide (4 mg) (Kenalog 40; Apothecon, Princeton, NJ, USA) in $0.1 \mathrm{ml}$ was injected using 27 -guage needle in the inferotemporal quadrant, 3.5 and $4 \mathrm{~mm}$ posterior to the limbus in pseudophakic and phakic eyes, respectively. Indirect ophthalmoscopy was performed to confirm the location of intravitreal suspension and status of the optic nerve head and central retinal artery. Chloramphenicol ointment was applied and eye was padded for $24 \mathrm{~h}$. All eye received post injection course of Chloramphenicol drops four times a day for 5 days.

Patients were examined postoperatively at 1 day, 1 week, 1 month, 3 months, and 6 months. OCT was performed postoperatively at 1, 3, and 6 months. An independent observer (SJ) performed pre- and postoperative VA assessment and OCT measurements. All patients were advised to return immediately if they experienced pain or loss of vision.

\section{Results}

In total, 18 female and 20 male subjects were enrolled. The mean age was $65 \pm 9$ years. Six $(16 \%)$ patients had insulin-dependant Diabetes Mellitus and 32 (84\%) had non-insulin-dependant Diabetes Mellitus. Mean duration of Diabetes Mellitus was $13.4 \pm 7$ years. Preoperative VA (LogMar) (mean \pm SD) was $0.905 \pm 0.23$. Intraocular pressure (IOP) (mean \pm SD) was $16 \pm 2.89 \mathrm{mmHg}$. OCT macular thickness (mean $\pm \mathrm{SD}$ ) at baseline was $418.7 \pm 104.2 \mu \mathrm{m}$. Eight eyes (21\%) were pseudophakic for which cataract surgery had been performed at least 6 months before IVTA. None of the eyes had previously undergone pars plana vitrectomy. Statistical significance was determined by paired Student's $t$-test.

At 1 month postoperatively, VA (mean \pm SD) improved from $0.905 \pm 0.23$ to $0.605 \pm 0.28(P<0.001)$ and OCT macular thickness (mean $\pm \mathrm{SD}$ ) decreased from $418.7 \pm 104.2 \mu \mathrm{m}$ at baseline to $276.9 \pm 72.6 \mu \mathrm{m}$ $(P<0.0001)$. At 3 month postoperatively, VA (mean \pm SD) was $0.555 \pm 0.29(P<0.001)$ and OCT macular thickness
(Figure 1) (mean \pm SD) was $250.6 \pm 53.1 \mu \mathrm{m}(P<0.001)$. At 6 month postoperatively, VA (mean \pm SD) was $0.730 \pm 0.30(P<0.04)$ and OCT macular thickness $($ mean $\pm \mathrm{SD})$ was $308.8 \pm 87.3 \mu \mathrm{m}(P<0.01)$. An example is illustrated in Figure 1.

Of 38 patients, $30(79 \%)$ patients experienced visual improvement of two or more lines on ETDRS chart at 1 months of follow up. Of 38 patients, 21 (55\%) patients experienced visual improvement of two or more lines on ETDRS chart at 3 months of follow up. At 6 months of follow up, 14 of 38 patients (36\%) patients experienced visual improvement of two or more lines on ETDRS chart. In eight of 38 patients $(21 \%)$, VA remained unchanged during the postoperative course of 6 months but these patients claimed subjective improvement in VA especially their reading ability. At 6 months of follow up, in 24 of 38 patients (63\%) VA declined to baseline with corresponding increase in OCT macular thickness. None of the patients experienced deterioration of VA from baseline during the study period.

Eyes, which demonstrated high reflectivity of the inner retina on OCT, were noted to have a greater VA increase. However, due to the limited numbers involved, this observation failed to reach significance.

IOP increased by more than $30 \%$ of baseline in six of 38 patients $(16 \%)$ but all were controlled successfully with monotherapy, and glaucomatous injury to the optic nerve disc was not observed during the course of the study. No patient required antiglaucoma treatment for greater than 6 months.

\section{Discussion}

Jonas and Sofker ${ }^{8}$ were the first to present a case report describing the use of IVTA in the management of diffuse DME, which was based on the potential antioedematous affect of cortisone. In this case study, the patient's VA improved from 0.1 to 0.3 at 3 months. Subsequently, Martidis et $a l^{9}$ presented a prospective case series of 16 patients who underwent IVTA injection for DME, which was refractory to laser. In that series, VA improved by 2.4, 2.4, and 1.3 Snellen lines at 1, 3, and 6 months, respectively. There was a corresponding parallel decrease in central macular thickness found on OCT examination. Subsequently, Jonas et $a l^{10}$ published a similar effect of IVTA in a prospective case series of 26 patients. However, while Massin et $a l^{11}$ demonstrated a significant decrease in central macular thickness in 15 eyes compared to control, they failed to demonstrate a corresponding significant improvement in VA. These authors identified the potential for IVTA in the treatment for refractory DME.

Our study suggests that IVTA may be beneficial in the management of diffuse DME. The majority of our 

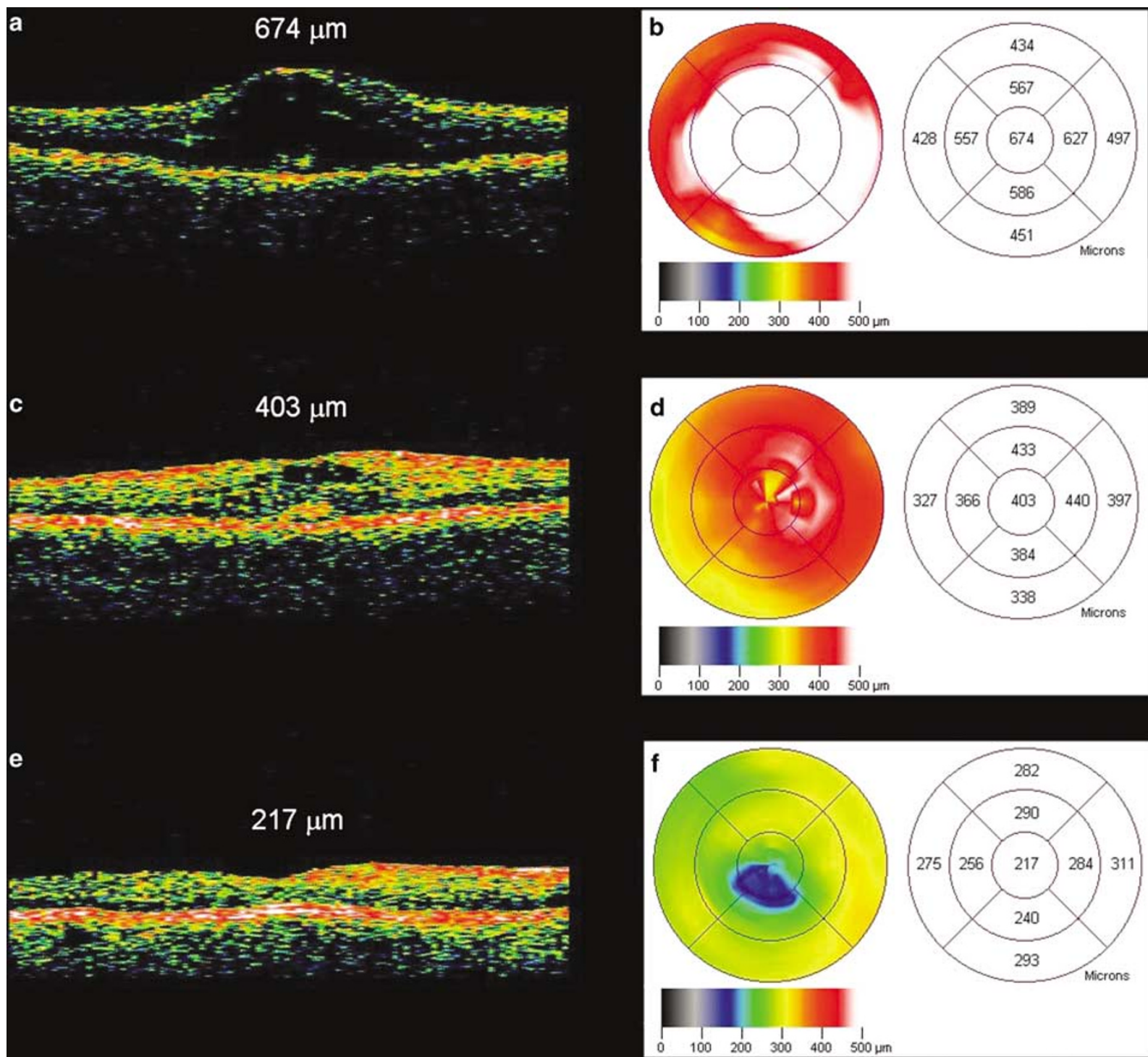

Figure 1 A 63-year-old female subject with refractory diffuse DME after two previous laser treatments. (a) Preoperative OCT cross-section of macula showing macular thickness $674 \mu \mathrm{m}$. (b) False colour topographic map of macula demonstrating macular oedema. (c) At 1 month after IVTA, macular thickness decreased to $403 \mu \mathrm{m}$. (d) False colour topographic map of macula demonstrating reduction of macular oedema. (e) At 3 months after IVTA, macular thickness was $217 \mu$ m. (f) False colour topographic map showing resolution of macular oedema.

patients showed a significant decrease in mean macular thickness at 3 months following IVTA injection and this was paralleled by a corresponding improvement in VA. However, at 6 months post IVTA injection, VA showed a tendency to decline and this was associated with an increase in central macular thickness on OCT. It is possible that this time frame of IVTA effect may be related to the clearance rate of triamcinolone from the vitreous cavity. Beer et $a l^{12}$ recently demonstrated that in normal phakic and nonvitrectomised human eyes, the half-life of $4 \mathrm{mg}$ of IVTA is 18.6 days. The group also found that a measurable concentration of triamcinolone would be expected to last for approximately 3 months
$(93 \pm 28$ days) in the vitreous. This clearance rate would tend to mirror the duration of the IVTA effect.

These findings support the short-term effectiveness of IVTA use and are similar to the findings of Sutter et $\mathrm{l}^{13}$ in a prospective, randomized, double-masked, placebocontrolled clinical trial, who demonstrated that 18 of 33 eyes $(55 \%)$ treated with IVTA gained five or more letters of best-corrected VA.

Interestingly, eyes with higher reflectivity of inner retina on OCT achieved greater VA increase than eyes with lower reflectivity of inner retina. It may be hypothesised that a lower optical reflectivity of inner retinal layers may demonstrate atrophy of the same, thus 
resulting in a failure of VA recovery in these patients. However, this observation failed to reach significance due to limited number of cases involved.

The precise mechanism of action of triamcinolone on retinal oedema is unknown. However, it has been hypothesised that cortisone may affect the permeability of the inner blood retinal barrier. Antonetti et al ${ }^{14}$ demonstrated a direct effect of steroids on retinal endothelial cell barrier properties, which was coincident with changes in occluden content, phosphorylation, and tight junction assembly. It is also known that corticosteroids may downregulate the production of vascular endothelial growth factor (VEGF) and it has been postulated that through the inhibition of the VEGF pathway that the breakdown of the blood retinal barrier is effected. ${ }^{15}$

In our study there were no major complications observed from IVTA. A $30 \%$ increase in IOP from baseline was observed in $16 \%$ of patients. However, this was adequately controlled by monotherapy alone in all patients and no patient required treatment after 6 months. No glaucomatous optic nerve damage was observed to have occurred in any patient. An increase in IOP following IVTA has been reported to occur in $25-70 \%$ of cases. Jonas et $a l^{16}$ reported an IOP increase of greater that $25 \mathrm{mmHg}$ in $52 \%$ of cases. They reported that eyes with existing glaucoma tended to have a larger IOP rise and they also found that, a raised IOP did not occur with subsequent injections in eyes with no IOP response at first injection. They observed that the rise in IOP was reversible at 6 months and easily controlled with medical treatment alone.

We acknowledge the risk of infective endophthalmitis, while no case of endophthalmitis was observed in our study, both infectious and noninfectious endophthalmitis have been reported as serious complications of IVTA use. Moshfeghi et al $^{17}$ reported an incidence of endophthalmitis of $0.87 \%$ in a large multicentre series involving 922 cases. They identified an increased risk in patients with diabetes mellitus, the use of multiuse bottles of triamcinolone, glaucomatous filtering blebs, and the presence of blepharitis.

Noninfectious or pseudo-endophthalmitis has also been reported to occur with an incident ranging from 0.015 to $6.7 \%$. Nelson et $a l^{18}$ reported seven cases of noninfectious endophthalmitis. All presented within 2 days after the injection, with blurred vision, hypopyon, and variable pain. In these eyes, the hypopyon and symptoms rapidly resolved without treatment. Roth et $\mathrm{l}^{19}$ suggested it may be appropriate to closely observe noninfectious, toxic endophthalmitis in patients treated with intravitreal triamcinolone before assuming it to be infectious, especially in the absence of eye pain.
This study demonstrates that IVTA may be a potential treatment for patients with diffuse DME refractory to laser treatment. We have demonstrated that IVTA temporarily improves VA in this population of patients. We acknowledge that this study is limited in that it is a small prospective case series without control. However, this study supports the need for further examination of this treatment modality and suggests that a larger prospective randomised control trial be performed to further assess the safety and efficacy of IVTA in these patients.

\section{Acknowledgements}

We acknowledge the help from Alf Whyte, Clinical Ophthalmic Photographer, Department of ophthalmology, Cork University Hospital Cork, Ireland.

\section{References}

1 Chew EY, Ferris III FL. Nonproliferative diabetic retunopathy. In: Ryan SJ (ed). Retina. Mosby Inc.: St Louis, 2001, pp 1295-1308.

2 Lee CM, Olk RJ. Modified grid laser photocoagulation for diffuse diabetic macular edema: long term visual results. Ophthalmology 1991; 98: 1594-1602.

3 Park $\mathrm{CH}$, Jaffe GJ, Fakrat S. Intravitreal triamcinolone acetonide in eyes with cystoid macular oedema associated with central retinal vein occlusion. Am J Ophthalmol 2003; 136: 419-425.

4 Jonas JB, Kreissig I, Degenring RF. Intravitreal triamcinolone acetonide for pseudophakic cystoid macular oedema. Am J Ophthalmol 2003; 136: 384-386.

5 Saraiva VS, Sallum JM, Farah ME. Treatment of cystoid macular oedema related to retinitis pigmentosa with intravitreal triamcinolone acetonide. Ophthalmic Surg Lasers Imaging 2003; 34: 398-400.

6 Ciardella AP, Klancnik J, Schiff W, Barile G, Langton K, Chang S. Intravitreal triamcinolone for the treatment of refractory diabetic macular oedema with hard exudates: an optical coherence tomography study. Br J Ophthalmol 2004; 88: 1131-1136.

7 Hee MR, Puliafito CA, Duker JS, Reichel E, Coker JG, Wilkins JR et al. Topography of diabetic macular oedema with optical coherence tomography. Ophthalmology 1998; 105: 360-370.

8 Jonas JB, Sofker A. Intraocular injection of crystalline cortisone as adjunctive treatment of diabeticmacular edema. Am J Ophthalmol 2001; 32: 425-427.

9 Martidis A, Duker JS, Greenberg PB, Rogers AH, Puliafito $\mathrm{CA}$, Reichel $\mathrm{E}$ et al. Intravitreal triamcinolone for refractory diabetic macular edema. Ophthalmology 2002; 109: 920-927.

10 Jonas JB, Kreissig I, Sofker A, Degenring RF. Intravitreal injection of triamcinolone for diffuse diabetic macular edema. Arch Ophthalmol 2003; 121: 57-61.

11 Massin P, Audren F, Haouchine B, Erginay A, Bergmann JF, Benosman $\mathrm{R}$ et al. Intravitreal triamcinolone acetonide for diabetic diffuse macular edema: preliminary results of a prospective controlled trial. Ophthalmology 2004; 111: 218-224. 
12 Beer PM, Bakri SJ, Singh RJ, Liu W, Peters 3rd GB, Miller M Intraocular concentration and pharmacokinetics of triamcinolone acetonide after single intravitreal injection. Ophthalmology 2003; 110: 681-685.

13 Sutter FK, Simpson JM, Gillies MC. Intravitreal triamcinolone for diabetic macular edema that persists after laser treatment: three-month efficacy and safety results of a prospective, randomized, double-masked, placebo-controlled clinical trial. Ophthalmology 2004; 111: 2044-2049.

14 Antonetti DA, Barber AJ, Khin S, Lieth E, Tarbell JM, Gardner TW. Vascular permeability in experimental diabetes is associated with reduced endothelial occludin content: vascular endothelial growth factor decreases occludin in retinal endothelial cells. Penn State Retina Res Group Diabetes 1998; 47: 1953-1959.

15 Brooks Jr HL, Caballero Jr S, Newell CK. Vitreous levels of vascular endothelial growth factor and stromal-derived factor 1 in patients with diabetic retinopathy and cystoid macular edema before and after intraocular injection of triamcinolone. Arch Ophthalmol 2004; 122: 1801-1807.

16 Jonas JB, Kreissig I, Degenring R. Intraocular pressure after intravitreal injection of triamcinolone acetonide. $\mathrm{Br} J$ Ophthalmol 2003; 87: 24-27.

17 Moshfeghi DM, Kaiser PK, Scott IU, Sears JE, Benz M, Sinesterra JP et al. Acute endophthalmitis following intravitreal triamcinolone acetonide injection. Am J Ophthalmol 2003; 136: 791-796.

18 Nelson ML, Tennant MT, Sivalingam A, Regillo CD, Belmont JB, Martidis A. Infectious and presumed noninfectious endophthalmitis after intravitreal triamcinolone acetonide injection. Retina 2003; 23 686-691.

19 Roth DB, Chieh J, Spirn MJ, Green SN, Yarian DL, Chaudhry NA. Noninfectious endophthalmitis associated with intravitreal triamcinolone injection. Arch Ophthalmol 2004; 122: 1733. 